\begin{abstract}
BACKGROUND: Multiple sclerosis (MS) is an autoimmune disorder, with a considerable genetic influence on susceptibility and disease course. Cytokines play an important role in MS pathophysiology, and genes encoding various cytokines are logical candidates to assess possible associations with MS susceptibility and disease course. We previously reported an association of a combination of polymorphisms in the interleukin (IL)-1B and $I L-1$ receptor antagonist $(I L$ $1 R N$ ) genes (i.e. $I L-1 R N$ allele $2+/ I L-1 B^{+3959}$ allele 2-) with disease severity in MS. Extending this

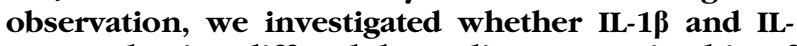
1 ra production differed depending on carriership of this gene combination.

Methods: Twenty MS patients and 20 controls were selected based upon carriership of the specific

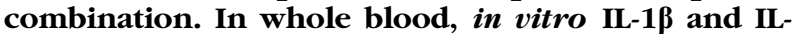
1 ra production was determined by enzyme-linked immunosorbent-assay after 6 and $24 \mathrm{~h}$ of stimulation with lipopolysaccharide.

Results: Carriers of the specific combination produced more IL-1ra, especially in MS patients, although not significantly. IL-1ra production was significantly higher in individuals homozygous for $I L-1 R N$ allele 2 . In patients, Il-1ra production was higher and IL-1ß production lower compared with controls. In primary progressive patients, the IL-1及 / IL-1ra ratio was significantly lower than in relapsingremitting patients.

Conclusion: Our results suggest higher in vitro IL-1 ra production in carriers of $I L-1 R N$ allele 2 , with an indication of an allelic dose-effect relationship.
\end{abstract}

Key words: Genetics, Interleukin-1, Interleukin-1 receptor antagonist, Multiple sclerosis, Cytokines

\section{Interleukin (IL)-1 gene polymorphisms: relevance of disease severity associated alleles with IL-1 $\beta$ and IL-1ra production in multiple sclerosis}

\author{
Hans M. Schrijver ${ }^{\mathrm{CA}, 1}$, Jaco van $\mathrm{As}^{2}$, \\ J. Bart A. Crusius ${ }^{3}$, Christien D. Dijkstra ${ }^{2}$ and \\ Bernard M. J. Uitdehaag ${ }^{1,4}$
}

${ }^{1}$ Department of Neurology, Vrije Universiteit Medical Centre, P.O. Box 7057, 1007 MB, Amsterdam, The Netherlands; ${ }^{2}$ Department of Cell Biology and Immunology, Vrije Universiteit Medical Centre, Van der Boechorststraat 7, 1081 BT, Amsterdam, The Netherlands; ${ }^{3}$ Department of Gastroenterology and Lab for Gastrointestinal Immunogenetics, Vrije Universiteit Medical Centre, Van der Boechorststraat 7, 1081 BT, Amsterdam, The Netherlands;

${ }^{4}$ Department of Epidemiology and Biostatistics, Vrije Universiteit Medical Centre, Van der Boechorststraat 7, 1081 BT, Amsterdam, The Netherlands

\footnotetext{
${ }^{\mathrm{CA}}$ Corresponding Author

Tel: + 31204440718

Fax: +31204442800

E-mail: HM.Schrijver@vumc.nl
}

\section{Introduction}

Genetics of multiple sclerosis

Multiple sclerosis (MS) is a chronic inflammatory disease of the central nervous system with a presumed auto-immune etiology. There is a strong genetic influence, with a concordance rate in monozygotic twins of approximately $30 \%{ }^{1}$ The genetics of MS are thought to comprise a variety of genes, influencing both disease susceptibility and disease characteristics. Among these, the contribution of genes encoding cytokines is currently under elaborate investigation, as cytokines are important mediators in immune and inflammatory conditions, such as multiple sclerosis. Due to the large and still increasing number of cytokines and the complexity of their interactions, the mechanisms by which they apparently influence the outcome of disease processes are poorly understood.
Interleukin-1 and interleukin-1 receptor antagonist

Interleukin (IL)- $1 \alpha$ and IL-1 $\beta$ are major pro-inflammatory cytokines, their actions being counter-regulated by the naturally occurring IL-1 receptor antagonist. $^{2}$ Several reports attribute a role to cytokines of the IL- 1 family in MS pathophysiology. IL-1 is present in and around MS lesions, and might be involved in the destruction of central nervous system myelin. ${ }^{3}$ Both during relapses and after interferon treatment, elevated IL-1ra levels are present in sera of MS patients, ${ }^{4}$ and there is some evidence that an increase in disease activity is followed by increased IL-1ra serum levels. ${ }^{5}$ Differences in either absolute cytokine production or in the ratio of pro-inflammatory and anti-inflammatory cytokines may influence the disease course; for example, by maintaining inflammatory activity. 


\section{Gene polymorphisms}

In the IL-1 genes, like in several other cytokine genes, polymorphisms have been demonstrated, ${ }^{6,7}$ adding an additional level of variation. Various associations of gene polymorphisms and disease characteristics have been published. A number of studies associate $I L-1 R N$ allele 2 with disease severity in chronic inflammatory conditions, such as systemic lupus erythematosus $^{8}$ and ulcerative colitis. ${ }^{9}$ We reported earlier an association of a specific $I L-1 B^{+3959} / I L-1 R N$ gene combination with disease severity in MS. ${ }^{10}$ In this study, carriers of a specific combination $(I L-1 R N$ allele $2+/ I L-1 B^{+3959}$ allele $2-$ ) had a significantly higher progression rate, measured as time from disease onset to an Expanded Disability Status Scale score equivalent with a walking distance of $100 \mathrm{~m}$. The observed associations might be explained by functional consequences of these gene polymorphisms. Assuming that cytokine production is regulated by the polymorphism present in the encoding gene, specific alleles might be linked to high or low production levels. This has been demonstrated for some polymorphisms in genes of the IL-1 family. ${ }^{6,11,12}$ Furthermore, it was shown very recently that innate production of IL-1 $\beta$ and IL-1ra is a risk factor for susceptibility and progression of relapseonset MS. ${ }^{13}$

\section{Study rationale}

In an attempt to explain our earlier observation, we investigated in patients and controls whether in vitro IL-1 $\beta$ and IL-1ra production differed between carriers and non-carriers of an $I L-1 R N / I L-1 B^{+3959}$ gene combination, previously shown to be associated with disease severity in MS.

\section{Methods}

\section{Study design}

All subjects were unrelated Dutch white Caucasian individuals. The study was carried out with approval of the Medical Ethical Committee and informed consent was obtained from all subjects. A biallelic polymorphism at position +3953 in the fifth exon of the $I L-1 B$ gene $^{6}$ and a penta-allelic polymorphism in intron 2 of the $I L-1 R N$ gene ${ }^{7}$ had been determined for all subjects according to previously described methods. ${ }^{9}$ We selected from our original study population of 148 MS patients in which we had established an association with disease severity ${ }^{10} 10$ patients that were carriers of the specific combination (i.e. $I L-1 R N$ allele $2+/ I L-1 B^{+3959}$ allele $2-$ ) and 10 patients that were non-carriers $\left(I L-1 R N\right.$ allele $2-/ I L-1 B^{+3959}$ allele $2-$ ). Carriers and non-carriers were matched for gender, and type of disease. Each patient group consisted of four relapsing-remitting, four secondary progressive and two primary progressive patients. Likewise, 20 healthy controls that were carrier (nine controls) or non-carrier (11 controls) of the specific combination were selected. This design defined two subgroups of 20 subjects (patients and controls) differing only in carriership of $I L-1 R N$ allele 2 . Subjects with exacerbations, steroid treatment, or infections within the past 3 months were excluded in order to avoid blood sampling in conditions that influence cytokine production. Due to deviations of the laboratory protocol the data of two controls were discarded, and the results are correspondingly based on the remaining 18 control subjects.

\section{Whole blood stimulation}

Blood was collected in two $4 \mathrm{ml}$ endotoxin-free sodium heparin tubes (Chromogenix AB, Mölndal, Sweden) and whole blood samples were diluted 1:1 with endotoxin free RPMI 1640 (Flow Laboratories, Rockville, MD, USA) and incubated with the appropriate stimuli within $60 \mathrm{~min}$ after sampling. The production of cytokines was measured after stimulation with Escherichia coli serotype 0111;B4 lipopolysaccharide (LPS; Difco Laboratories, Detroit, MI, USA) at a final concentration of $10 \mathrm{ng} / \mathrm{ml}$ of LPS for 6 and $24 \mathrm{~h}$ in 96 -well tissue culture plates at $37^{\circ} \mathrm{C}$ and $5 \% \mathrm{CO}_{2}$. The supernatants were centrifuged for 10 min and stored at $-20^{\circ} \mathrm{C}$ until assay with commercially available IL-1ra and IL-1 $\beta$ enzyme-linked immunosorbent assay kits (Biosource Europe S.A., Fleurus, Belgium). Incubation times were chosen on the basis of production curves generated from preliminary data of healthy volunteers. Procedures were performed according to the manufacturer's instructions. For every subject samples were run in duplicate with and without LPS stimulation, as control for contamination. Results are expressed in picograms per milliliter. Whole blood was used to maintain cell types in their in vivo ratios and to retain all blood components. As significant relations between cytokine production in peripheral blood mononuclear cells (PBMCs) and whole blood cultures have recently been reported, ${ }^{14}$ comparisons with studies using peripheral blood mononuclear cells can be reliably made.

\section{Statistical analysis}

Production levels between groups and within groups were analyzed using one-way/two-way analysis of variance, Mann-Whitney and Kruskal-Wallis tests. Correlations were calculated using Spearman's rank correlation test. Significance levels were set at 5\% (two sided, $p=0.05$ ), and $p<0.10$ was considered a trend. 


\section{Results}

Relevant features of patients and controls are summarized in Table 1. Baseline levels (without stimulation) were all below $300 \mathrm{pg} / \mathrm{ml}$. Average cytokine levels after LPS stimulation in patients and controls are shown in Figs. 1 and 2. Cytokine levels after 6 and 24 h correlated significantly $(p<0.01)$ for both IL-1ra $(r=0.83)$ and IL-1 $\beta(r=0.90)$.

\section{IL-1ra production}

IL-1ra production was considerably higher in IL-1RN allele 2 carriers (MS and controls combined) than in non-carriers after 6 and 24 h (Fig. 1; 24\% and 21\%, respectively), although not significant $(p=0.16$ and $p=0.25)$. IL-1ra production was similar in MS patients and controls after $6 \mathrm{~h}$, but considerably higher (18\%) after $24 \mathrm{~h}$ stimulation $(p=0.303)$. The higher production in MS patients was due to elevated levels $(36 \%)$ in the $I L-1 R N$ allele $2+/ I L-1 B^{+3959}$ allele 2 - group. Although IL-1ra levels after 6 h were $16 \%$ higher in $I L-1 R N$ allele $2+/ I L-1 B^{+3959}$ allele $2-$ controls, $24 \mathrm{~h}$ levels did not differ between $I L-1 R N$ allele 2 carriers and non-carriers (Fig. 2). The observed differences were not statistically significant. There was a trend $(p=0.095)$ towards higher production in controls and patients homozygous for $I L$ $1 R N$ allele 2 after $6 \mathrm{~h}$, and a significant difference after $24 \mathrm{~h}$ (Fig. 3; $p=0.043$ ). Gender, age and disease type did not influence cytokine production significantly.

\section{IL-1 $\beta$ production}

A trend towards higher IL- $1 \beta$ production in controls compared with patients after $6 \mathrm{~h}(32 \%)$ and $24 \mathrm{~h}$ (27\%) stimulation was observed $(p=0.80$ and $p=$ 0.094). Also, a trend in primary progressive patients to produce less IL-1 $\beta$ after $24 \mathrm{~h}$ than relapsingremitting or secondary progressive patients was seen $(44 \% ; p=0.059)$. No significant differences were observed with regard to genotype, age or gender.

Table 1. Characteristics of MS patients and controls

\section{IL-1 $\beta$ /IL-1ra ratio}

Assuming that a higher IL-1 $\beta /$ IL-1ra ratio reflects enhanced pro-inflammatory activity, this ratio was calculated from the cytokine production levels. No significant differences were observed with regard to genotype or gender. A significantly lower IL-1 $\beta / \mathrm{IL}-1$ ra ratio was observed in primary progressive patients compared with relapsing remitting patients, with a ratio of 0.37 versus 1.14 after $6 \mathrm{~h}(p=0.038)$ and of 0.17 versus 0.45 after $24 \mathrm{~h}(p=0.017$; Table 2$)$. Both higher IL-1ra levels and lower IL-1 $\beta$ levels in the primary progressive patients underlie the observed difference.

\section{Discussion}

In 1999 we established an association of a specific combination of polymorphisms in the $I L-1 B$ and $I L$ $1 R N$ genes (i.e. $I L-1 R N$ allele $2+/ I L-1 B^{+3959}$ allele $2-)$ with disease severity in MS. ${ }^{10}$ Although a large study in the UK did not show any evidence in favor of a role for the $I L-1 R N$ gene in susceptibility to MS or its progression, ${ }^{15}$ other reports provided support for our original observation that polymorphisms in the IL-1 gene cluster are associated with disease severity. ${ }^{16,17}$ Furthermore, the production of IL-1ra and IL-1 $\beta$ has very recently been proposed as a risk factor for susceptibility and progression of relapse-onset MS. ${ }^{13}$ Hence, in an effort to explain our observed association, this study addresses whether a specific genetic make-up of the IL-1 genes is reflected in cytokine production. Although other studies have shown that inter-individual cytokine production is highly variable, intra-individual production is remarkably stable over time and appears to be characteristic of an individual. ${ }^{11,14}$ In addition, we tried to limit influence of disease activity on cytokine production by blood sampling in periods without recent exacerbations. In favor of an effect on cytokine production is our observation that $I L-1 R N$ allele 2 carriers produced more IL-1ra than $I L-1 R N$ allele 2 non-carriers, as was anticipated from available data. ${ }^{11,18}$ Furthermore, there was in individuals (patients and controls) homozygous for $I L-1 R N$ allele 2 a consistent trend

\begin{tabular}{|c|c|c|c|c|}
\hline & \multicolumn{2}{|c|}{ MS patients $(n=20)$} & \multicolumn{2}{|c|}{ Controls $(n=18)$} \\
\hline & $I L-1 R N 2+/ I L-1 B^{+3959} 2-$ & $I L-1 R N 2-/ I L-1 B^{+3959} 2-$ & $I L-1 R N 2+/ I L-1 B^{+3959} 2-$ & $I L-1 R N 2-/ I L-1 B^{+3959} 2-$ \\
\hline Female & 3 & 3 & 3 & 6 \\
\hline Male & 7 & 7 & 4 & 5 \\
\hline Age $\pm \mathrm{SD}$ (years) & $43.4 \pm 12.7$ & $49.3 \pm 15.3$ & $30.9 \pm 5.2$ & $37.8 \pm 9.5$ \\
\hline $\mathrm{RR}$ & $4(3 \bar{M}, 1 F)$ & $4(3 \bar{M}, 1 \mathrm{~F})$ & & \\
\hline SP & $4(3 \mathrm{M}, 1 \mathrm{~F})$ & $4(3 \mathrm{M}, 1 \mathrm{~F})$ & Not applicable & Not applicable \\
\hline PP & $2(1 \mathrm{M}, 1 \mathrm{~F})$ & $2(1 \mathrm{M}, 1 \mathrm{~F})$ & & \\
\hline
\end{tabular}

RR, Relapsing-remitting; SP, secondary progressive; PP, primary progressive; SD, standard deviation; $M$, male; $F$, female. 


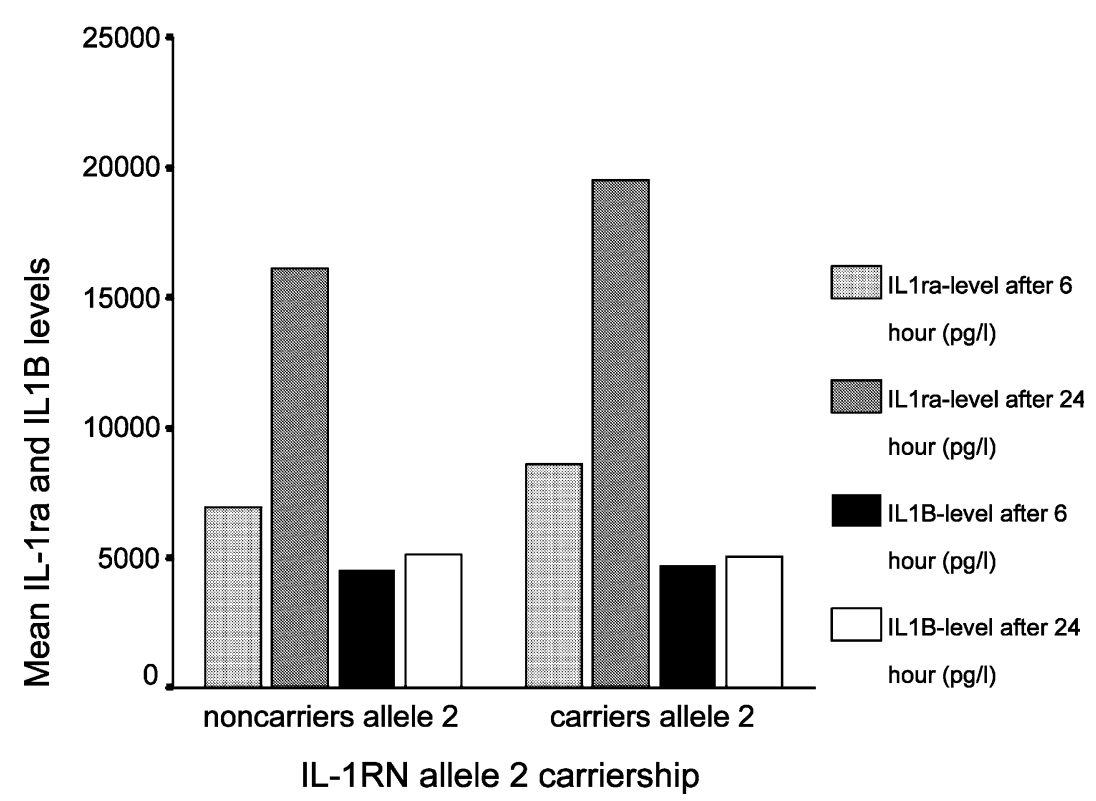

FIG. 1. IL-1ra and IL-1 $\beta$ levels after 6 and $24 \mathrm{~h}$ in carriers(IL-1RN allele $2+/ I L-1 B^{+3959}$ allele $\left.2-\right)$ and non-carriers (IL-1RN allele $2-/$ IL- $1 B^{+3959}$ allele $2-$ ) of IL-1RN allele 2.

towards higher IL-1ra production. This observation implies an allelic dose-effect relationship with regard to cytokine production, and is in line with an Italian study that showed that peripheral blood mononuclear cells from healthy controls homozygous for $I L-1 R N$ allele 2 produce significantly more IL-1ra. ${ }^{19}$

Unfortunately, due to the rarity of patients that are homozygous for $I L-1 R N$ allele 2 and non-carriers of $I L-1 B^{+3959}$ allele 2 , we were not able to further explore this observation in the present study. Despite the mentioned raised IL-1ra levels in $I L-1 R N$ allele 2 carriers, the observed differences between carriers and non-carriers of $I L-1 R N$ allele 2 did not reach statistical significance. Obviously, this argues against a major influence of the studied gene combination on cytokine production. What, then, to conclude from this and earlier research? First, it should be noted that the size of this exploratory study may hamper detection of differences in production levels. Second, it has been shown that IL-1ra production is not only determined by the $I L-1 R N$ gene polymorphisms, but is co-regulated by the $I L-1 B^{+3959}$ polymorphism. ${ }^{12}$ Given the specific gene combination that we investigated, all individuals are $I L-1 B^{+3959}$ allele 1 homozygous, and hence the observed differences in IL-1 $\beta$

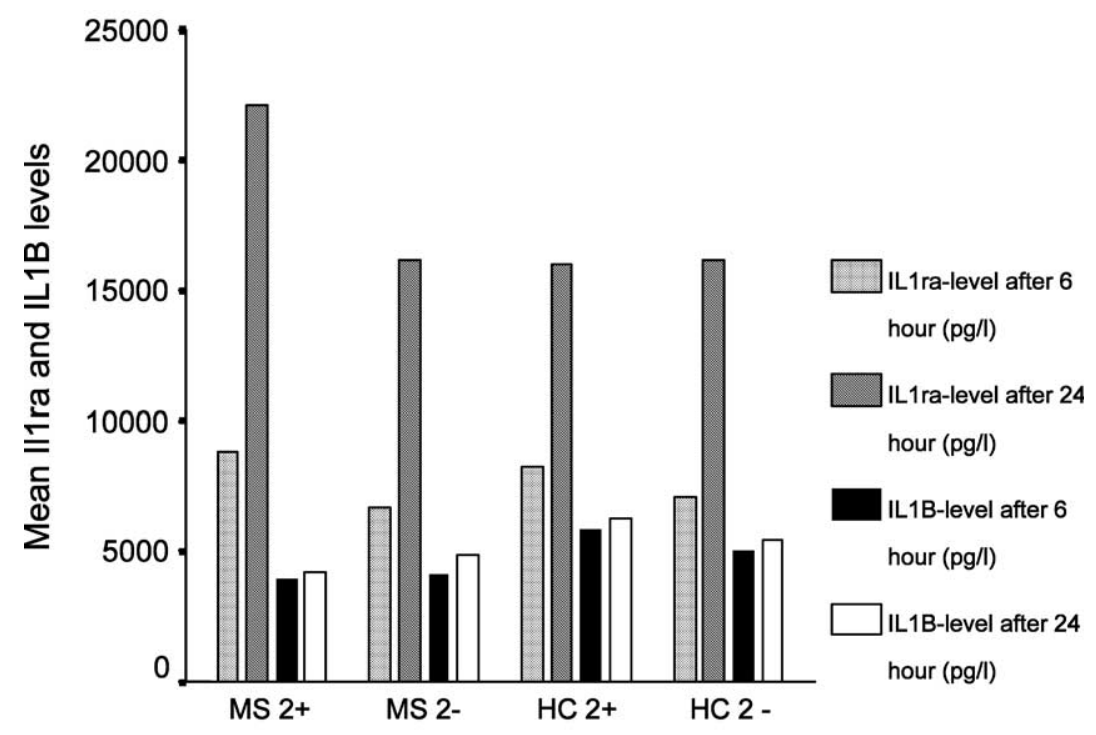

IL1 RN allele 2 carriership in patients and controls

FIG. 2. Mean IL-1ra and IL-1 $\beta$ levels after 6 and $24 \mathrm{~h}$ in MS patients and controls (HC) after stratification for IL-1RN allele 2 carriership. $2+, I L-1 R N$ allele $2+/ I L-1 \beta$ allele $2-; 2-, I L-1 R N$ allele $2-/ I L-1 \beta$ allele $2-$. 


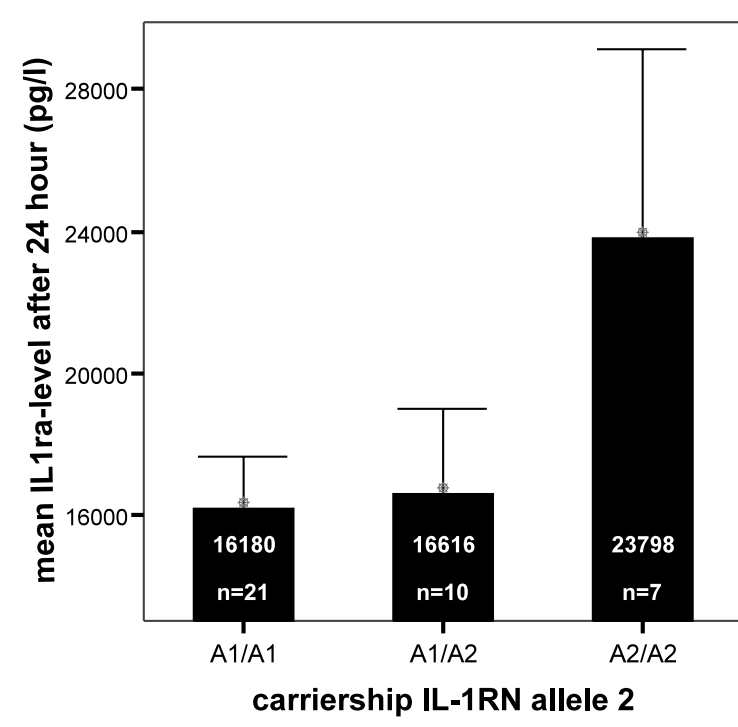

FIG. 3. Mean IL-1ra levels after $24 \mathrm{~h}$ and IL-1RN allele 2 number. Error bars represent standard error of mean; $n$, number of individuals; A1/A1, non-carriers of IL-1RN allele 2; A1/A2, carriers of one copy of IL-1RN allele 2; A2/A2, carriers of two copies of $I L-1 R N$ allele 2. $p P=0.043 \mathrm{~A} 2 / \mathrm{A} 2$ versus other genotypes.

Table 2. IL-1 $\beta / I L-1$ ra ratios after 6 and $24 \mathrm{~h}$

\begin{tabular}{|c|c|c|c|}
\hline & \multirow[t]{2}{*}{$n$} & \multicolumn{2}{|c|}{ IL-1 $\beta / I L-1$ ra } \\
\hline & & $6 \mathrm{~h}$ & $24 \mathrm{~h}$ \\
\hline \multicolumn{4}{|l|}{ Multiple sclerosis } \\
\hline Relapsing-remitting & 8 & 1.14 & 0.45 \\
\hline Secondary progressive & 8 & 0.52 & 0.25 \\
\hline Primary progressive & 4 & $0.37^{\mathrm{a}}$ & $0.17^{\mathrm{a}}$ \\
\hline All patients & 20 & 0.72 & 0.31 \\
\hline Controls (HC) & 18 & 0.77 & 0.40 \\
\hline IL-1RN allele 2 carriers (MS) & 10 & 0.56 & 0.25 \\
\hline IL-1RN allele 2 carriers (HC) & 7 & 0.78 & 0.46 \\
\hline IL-1RN allele 2 carriers (all) & 17 & 0.65 & 0.34 \\
\hline IL-1RN allele 2 non-carriers (MS) & 10 & 0.89 & 0.38 \\
\hline IL-1RN allele 2 non-carriers (HC) & 11 & 0.77 & 0.36 \\
\hline IL-1RN allele 2 non-carriers (all) & 21 & 0.82 & 0.37 \\
\hline
\end{tabular}

IL-1RN allele 2 carriers, IL-1RN allele $2+/ I L-1 B^{+3959}$ allele $2-;$ IL-1RN allele 2 non-carriers, IL-1RN allele $2-/ I L-1 B^{+3959}$ allele $2-; \mathrm{HC}=$ healthy controls.

a Primary progressive versus relapsing-remitting $(p=0.038$ and $p=$ 0.017, 6 and 24 h; Mann-Whitney test).

and IL-1ra production cannot be attributed to this gene polymorphism. In a recent report, despite significant differences in IL-1 $\beta$ and IL-1ra production levels between families of MS patients, no associations with $I L-1 B$ and $I L-R N$ gene polymorphisms were established, leading the authors to suggest that possibly other polymorphisms are responsible for the differences they observed. ${ }^{13}$

As a separate observation, unrelated to the gene polymorphisms, we found in primary progressive patients a trend towards lower production of IL-1 $\beta$ and significantly lower IL-1 $\beta /$ IL-1ra ratios (after 6 and $24 \mathrm{~h}$ ) than in relapsing-remitting patients. This is consistent with the current opinion that in primary progressive patients inflammation is a less prominent feature. ${ }^{20}$ Since only four primary progressive patients were included, our findings must of course be interpreted with caution.

In short, the findings of this study cannot be viewed, nor are they presented, as conclusive. They do suggest, however, higher IL-1ra production in carriers of the $I L-1 R N$ allele 2, with a possible allelic dose-effect relationship. Furthermore, the $I L-1 R N$ gene polymorphism might not be the only determinant of IL-1ra production, but other factors that could well be other gene polymorphisms are probably also involved. Larger studies combining clinical, genetic, and functional data (both in vitro and in vivo) are needed to obtain definite answers concerning the role of cytokine genes like those of the IL-1 gene cluster in MS and other diseases.

\section{References}

1. Dyment DA, Sadovnick AD, Ebers GC, Sadnovich AD. Genetics of multiple sclerosis. Hum Mol Genet 1997; 6: 1693-1698.

2. Arend WP. Interleukin 1 receptor antagonist. A new member of the interleukin 1 family. I Clin Invest 1991; 88: 1445-1451.

3. Brosnan CF, Cannella B, Battistini L, Raine CS. Cytokine localization in multiple sclerosis lesions: correlation with adhesion molecule expression and reactive nitrogen species. Neurology 1995; 45 (6 suppl 6): S16-S21.

4. Nicoletti F, Patti F, DiMarco R, et al. Circulating serum levels of IL-1ra in patients with relapsing remitting multiple sclerosis are normal during remission phases but significantly increased either during exacerbations or in response to IFN-beta treatment. Cytokine 1996; 8: 395-400.

5. Voltz R, Hartmann M, Spuler S, et al. Multiple sclerosis: longitudinal measurement of interleukin-1 receptor antagonist. J Neurol Neurosurg Psychiatry 1997; 62: 200-201.

6. Pociot F, Molvig J, Wogensen L, Worsaae H, Nerup J. A TaqI polymorphism in the human interleukin-1 beta (IL-1 beta) gene correlates with IL-1 beta secretion in vitro. Eur J Clin Invest 1992; 22: 396- 402 .

7. Tarlow JK, Blakemore AI, Lennard A, et al. Polymorphism in human IL-1 receptor antagonist gene intron 2 is caused by variable numbers of an 86-bp tandem repeat. Hum Genet 1993; 91: 403-404.

8. Blakemore AI, Tarlow JK, Cork MJ, Gordon C, Emery P, Duff GW Interleukin-1 receptor antagonist gene polymorphism as a disease severity factor in systemic lupus erythematosus. Arthritis Rheum 1994; 37: $1380-1385$.

9. Bioque G, Crusius JB, Koutroubakis I, et al . Allelic polymorphism in IL-1 beta and IL-1 receptor antagonist (IL-1Ra) genes in inflammatory bowel disease. Clin Exp Immunol 1995; 102: 379-383.

10. Schrijver HM, Crusius JB, Uitdehaag BM, et al. Association of interleukin-1beta and interleukin-1 receptor antagonist genes with disease severity in MS. Neurology 1999; 52: 595-599.

11. Danis VA, Millington M, Hyland VJ, Grennan D. Cytokine production by normal human monocytes: inter-subject variation and relationship to an IL-1 receptor antagonist (IL-1Ra) gene polymorphism. Clin Exp Immunol 1995; 99: 303-310.

12. Hurme M, Santtila S. IL-1 receptor antagonist (IL-1Ra) plasma levels are co-ordinately regulated by both IL-1Ra and IL-1beta genes. Eur $J$ Immunol 1998; 28: 2598-2602.

13. de Jong BA, Huizinga TW, Bollen EL, et al. Production of IL-1beta and IL-1Ra as risk factors for susceptibility and progression of relapse-onset multiple sclerosis. J Neuroimmunol 2002; 126: 172-179.

14. Yaqoob P, Newsholme EA, Calder PC. Comparison of cytokine production in cultures of whole human blood and purified mononuclear cells. Cytokine 1999; 11: 600-605.

15. Feakes R, Sawcer S, Broadley S, et al. Interleukin 1 receptor antagonist (IL-1ra) in multiple sclerosis. J Neuroimmunol 2000; 105: 96-101.

16. Kantarci OH, Atkinson EJ, Hebrink DD, McMurray CT, Weinshenker BG. Association of two variants in IL-1beta and IL-1 receptor antagonist genes with multiple sclerosis. J Neuroimmunol 2000; 106: 220-227.

17. Mann CL, Davies MB, Stevenson VL, et al. Interleukin 1 genotypes in multiple sclerosis and relationship to disease severity. J Neuroimmunol 2002; 129: 197-204.

18. Mandrup-Poulsen T, Pociot F, Molvig J, et al. Monokine antagonism is reduced in patients with IDDM. Diabetes 1994; 43: 1242-1247. 
19. Sciacca FL, Ferri C, Vandenbroeck K, et al. Relevance of interleukin receptor antagonist intron 2 polymorphism in Italian MS patients. Neurology 1999; 52: 1896-1898.

20. Thompson AJ, Polman CH, Miller DH, et al. Primary progressive multiple sclerosis. Brain 1997; 120: 1085-1096.
Received 8 October 2002

Accepted 16 January 2003 


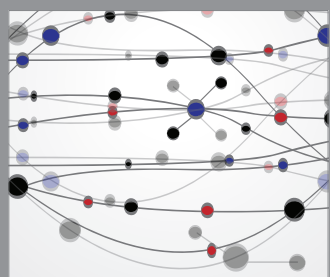

The Scientific World Journal
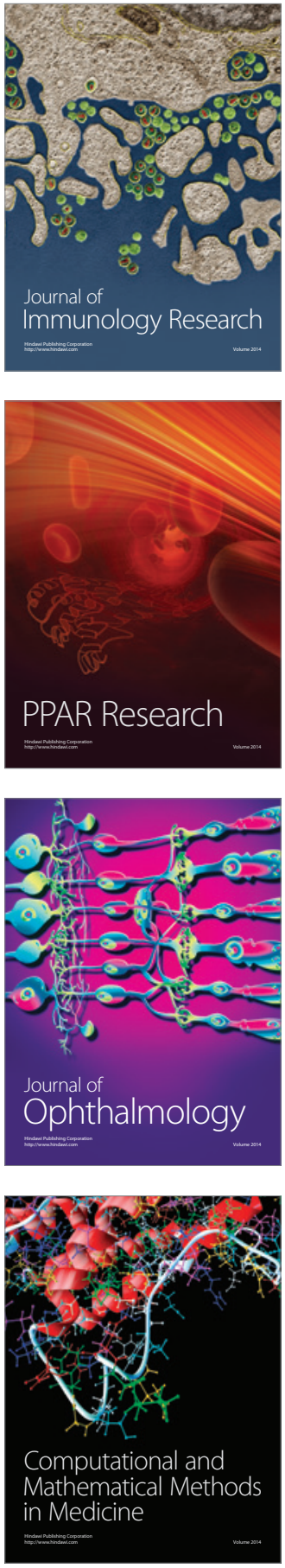

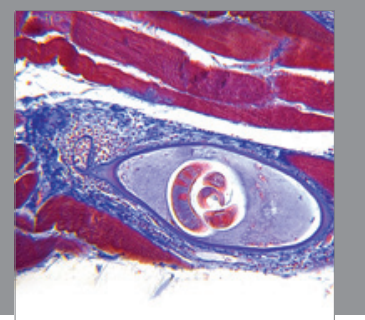

Gastroenterology

Research and Practice
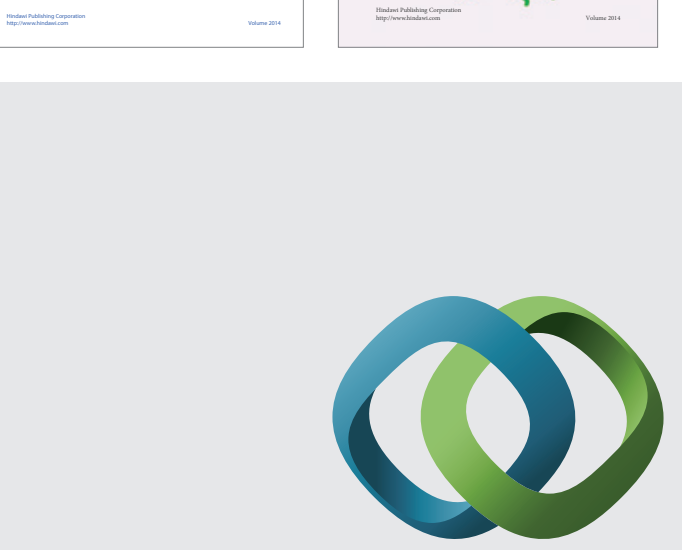

\section{Hindawi}

Submit your manuscripts at

http://www.hindawi.com
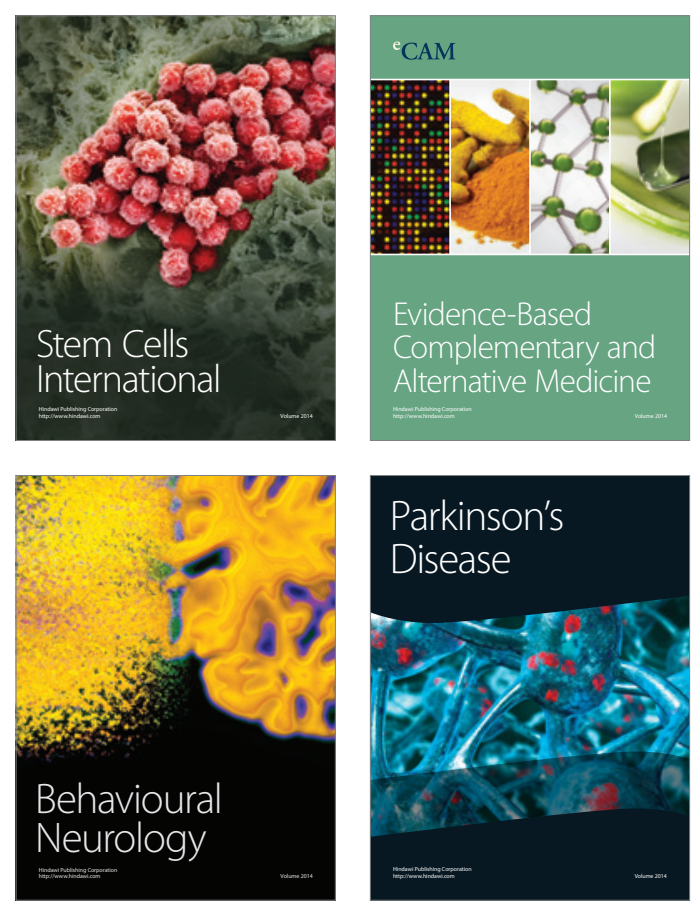

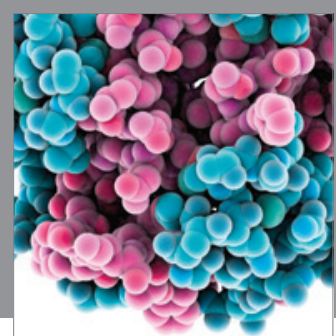

Journal of
Diabetes Research

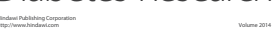

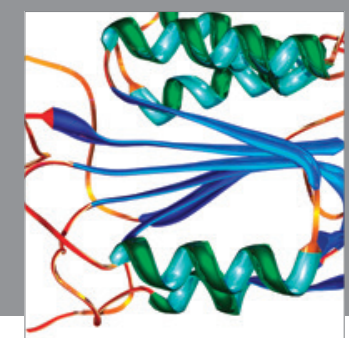

Disease Markers
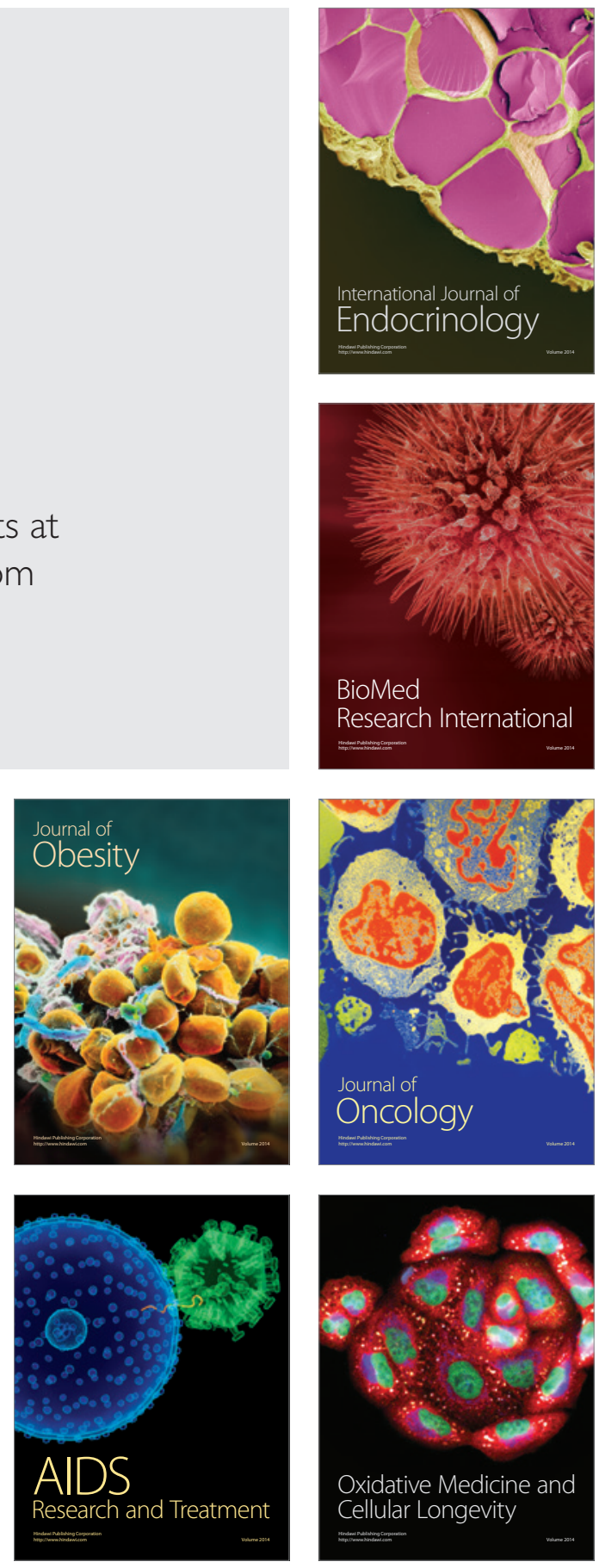